\title{
The regional association between bronchiectasis and lung cancer in chest CT
}

\author{
Yeon Wook Kim', Chang-Hoon Lee ${ }^{1}$, Kwang-Nam Jin², Jung-Kyu Lee ${ }^{3}$, Eun Young Heo ${ }^{3}$, Sung Soo Park ${ }^{3}$,
} Hee Soon Chung $^{3}$ and Deog Kyeom $\mathrm{Kim}^{3 *}$

\begin{abstract}
Background: Limited studies have examined the association between lung cancer and bronchiectasis (BE). This study evaluated the regional association between BE and lung cancer by analyzing the lobar location of lung cancer in patients with underlying BE.

Methods: This clustered multi-level study enrolled patients who had underlying BE and were newly diagnosed with lung cancer between January 1, 2010 and May 30, 2013 in two referral hospitals in South Korea. By analyzing the presence of lung cancer and underlying BE as event variables at the level of lung lobes on chest computed tomography (CT), we evaluated the association of BE and lung cancer by the locations of the diseases.

Results: Eighty-one patients with BE and combined lung cancer were enrolled. Within 486 lung lobes of the patients, combined BE and lung cancer in the same lobe was found in 11 lobes $(2.3 \%)$. Using the general estimating equation assuming $\mathrm{BE}$ as a risk factor of lung cancer, the results indicated that the prevalence of lung cancer was significantly lower in the lobes with pre-existing $B E(\beta=-1.09, p$-value $=0.001)$.
\end{abstract}

Conclusions: Regionally, pre-existing BE was associated with a lower risk of the occurrence of lung cancer in the same lobe.

Keywords: Bronchiectasis, Lung cancer, Regional association, Lung lobes, Chest CT

\section{Background}

Chronic inflammation plays a key role in carcinogenesis via disordered necrotic cell death, subsequent epithelial proliferation, and suppressed immunity [1]. Like other organs, chronic inflammation in the lung, such as chronic obstructive pulmonary disease (COPD), is associated with an increased risk of lung cancer, mainly related to repeated airway epithelial injury and accompanied high cell turnover rates [2-4].

Bronchiectasis (BE) is a representative chronic inflammatory airway disease characterized by abnormal and permanent dilatation of the bronchi, accompanied by high levels of inflammatory cytokines [5]. Unlike COPD, however, the impact of the inflammation accompanying $\mathrm{BE}$ on lung cancer remains unclear.

\footnotetext{
* Correspondence: kimdkmd@snu.ac.kr

${ }^{3}$ Division of Pulmonary and Critical Care Medicine, Department of Internal Medicine, Seoul National University College of Medicine, Seoul Metropolitan Government-Seoul National University Boramae Medical Center, 20

Boramaero-5-Gil, Dongjak-Gu, Seoul 156-707, Republic of Korea

Full list of author information is available at the end of the article
}

Considering reports on the influence of inflammatory signaling in carcinogenesis, chronic inflammation caused by $\mathrm{BE}$ might be associated with an increased risk of lung cancer because of the local effects of chronic inflammation caused by repeated airway injury and impaired mucociliary clearance. If this postulate holds, it is reasonable to think that the incidence or prevalence of cancer should be increased close to the pre-existing $\mathrm{BE}$ in location $[3,6,7]$.

However, there are only limited data on an association between $\mathrm{BE}$ and the risk of lung cancer. A few studies reported that patients with BE had elevated levels of serum transforming growth factor- $\beta 1$ (TGF- $\beta 1$ ), which is a potential protective factor against carcinogenesis $[5,8,9]$. In patients with cystic fibrosis showing radiological features of $\mathrm{BE}$, the cystic fibrosis gene mutation was inversely associated with some malignancies [10]. This supports the hypothesis that the association between $\mathrm{BE}$ and lung 
cancer is different from the previously reported role of inflammation in lung cancer carcinogenesis.

The aim of this study was to assess the association between $\mathrm{BE}$ and the risk of lung cancer by analyzing the lobar location of lung cancer in patients with underlying $\mathrm{BE}$.

\section{Methods}

\section{Study design and subjects}

We designed this multi-center-based, retrospective, clustered, multi-level study analyzing the presence of lung cancer and $\mathrm{BE}$ as event variables at the level of lung lobes in patients with underlying chronic $\mathrm{BE}$ who were newly diagnosed with lung cancer between January 1 , 2010 and May 30, 2013. We identified the patients older than 40 years with BE at two referral hospitals in South Korea: Seoul National University Boramae Medical Center and Seoul National University Hospital. Among them, the patients newly diagnosed with lung cancer in the study period were enrolled and analyzed. The flow diagram selecting study population for analyses is shown in Fig. 1. The design of this study was approved by the Institutional Review Board of Seoul National University Hospital (IRB No. H-1312-123-547) and Seoul National University Boramae Hospital (IRB No. 16-2014-137). The institutional review boards waived the need for written informed consent from the participants. Patient records were anonymized and de-identified prior to analysis.

Pre-existing BE was assessed and confirmed with chest computed tomography (CT) analyzed independently by a radiologist and a pulmonologist [11]. If inconsistent findings were found, a consensus decision was reached following a discussion. Patients were excluded if they had $\mathrm{BE}$ secondary to mechanical effects caused by lung cancer. Evaluation of secondary BE was based on comparison with previous CTs if available, and inspection of traction and bronchodilation caused by lung cancer (Additional file 1: Figure S1). Reviewing the chest CT findings, the locations of the previous $\mathrm{BE}$ and newly developed lung cancer were analyzed among lobes (the lingula of the left lung was considered a distinct lobe, giving six lobes per patient). Demographic data were collected from each patient, including smoking history, baseline spirometric measurements, severity index of $\mathrm{BE}$ calculated using the modified Bhalla system and the Reiff score, presence and severity of combined emphysema, tissue type and staging of the diagnosed lung cancer $[12,13]$.

Among the patients with combined emphysema, the severity of emphysema was assessed visually with $\mathrm{CT}$ images according to the modified Goddard scoring system $[14,15]$. Six images of three lung slices were evaluated for each patient (the right and left lungs evaluated separately). Each image was classified as normal (score 0 ), $\leq 5 \%$ affected (score 0.5 ), $\leq 25 \%$ affected (score 1 ), $\leq$ $50 \%$ affected (score 2), $\leq 75 \%$ affected (score 3) or $>75 \%$ affected (score 4). The average score of six images was considered as a representative value of the severity of emphysema in each patient, and the patients were further categorized into three groups as previously suggested [16]: no/mild emphysema (average severity score $<1$ ); moderate emphysema $(1 \leq$ average severity score $<2.5)$; and severe emphysema (average severity score $\geq 2.5$ ).

\section{Data analysis}

Age was given as the median and interquartile range (IQR), while other continuous variables were given as the means with the standard deviations. To evaluate correlations within a subject and within lobes by repeated measures of the events ( $\mathrm{BE}$ and lung cancer), generalized estimating equations were used and the $\beta$-value was calculated. To eliminate any possible interaction that might

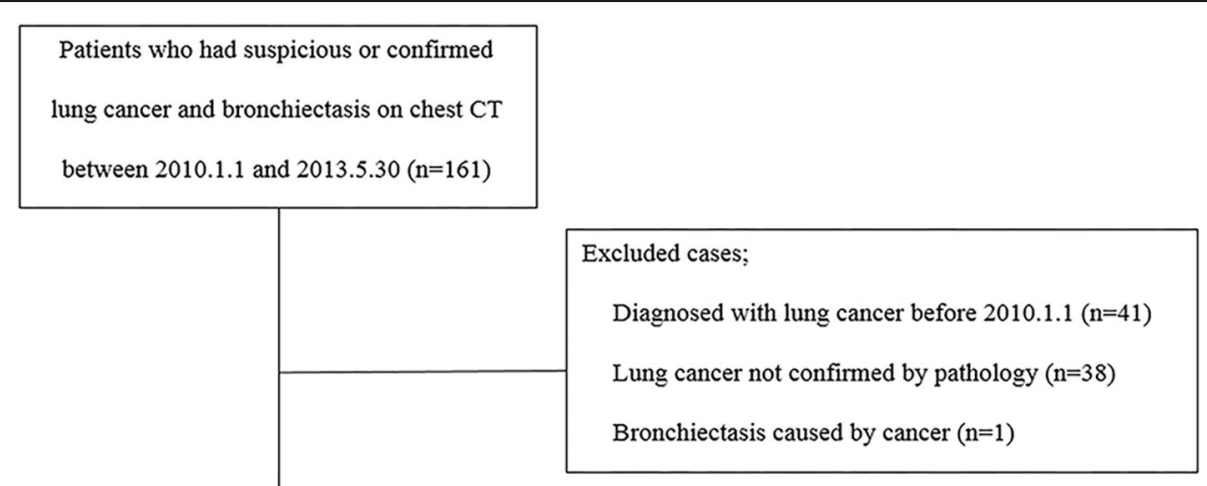

Patients diagnosed with lung cancer and

underlying bronchiectasis $(\mathrm{n}=81)$

Fig. 1 A Flow Diagram of the Study Population 
exist between smoking and $\mathrm{BE}$, analyses were further stratified by the smoking status of the patients. In addition, since emphysema is an important risk factor for lung cancer, subgroup analyses were performed in groups classified according to the presence and severity grade of emphysema. $P$-values $<0.05$ were recognized as indicative of statistical significance. All analyses were performed using the SPSS software, version 19.0 (SPSS Inc., Chicago, IL, USA).

\section{Results}

\section{Baseline characteristics of the study population}

Eighty-one patients with pre-existing $\mathrm{BE}$ were diagnosed with lung cancer during the study period. The baseline characteristics of the study participants are shown in Table 1 . The median age of the study population was 70 (IQR 61-76) years and 52 (64.2 \%) were male. Forty-four patients $(54.4 \%)$ had a history of exposure to smoking, and $53(65.4 \%)$ had no or mild emphysema in CT. The baseline spirometric results of the patients at the time of diagnosis with lung cancer included a mean $\mathrm{FEV}_{1} / \mathrm{FVC}$ ratio of 67.7 and mean predicted $\mathrm{FEV}_{1}$ of $87.9 \%$.

\section{Characteristics of diagnosed lung cancer}

Seventy-three patients $(90.1 \%)$ were diagnosed with nonsmall-cell lung cancer. Adenocarcinoma was the most common histological type (51.9 \%), followed by squamous cell carcinoma $(22.2 \%)$ and poorly differentiated

Table 1 Demographic Characteristics of the Study Population

\begin{tabular}{ll}
\hline Characteristics & $\begin{array}{l}\text { Patients with bronchiectasis and newly } \\
\text { diagnosed lung cancer }(n=81)\end{array}$ \\
\hline Age, years, median (IQR) & $70(61-76)$ \\
Male, $\mathrm{n}(\%)$ & $52(64.2)$ \\
Smoking history, $\mathrm{n}(\%)$ & \\
Current & $25(30.9)$ \\
Former & $19(23.5)$ \\
Never & $37(45.7)$ \\
Smoked pack-year, mean & $21.8 \pm 23.7$ \\
\pm SD & \\
Presence and severity of & \\
emphysema on CT, $\mathrm{n}(\%)$ & \\
No/mild emphysema & $53(65.4)$ \\
Moderate emphysema & $20(24.7)$ \\
Severe emphysema & $8(9.9)$ \\
Spirometry, mean \pm SD & \\
FEV1/FVC, ratio & $67.7 \pm 15.2$ \\
FEV1 predicted (\%) & $87.9 \pm 23.4$ \\
FVC predicted (\%) & $91.1 \pm 20.9$ \\
Charlson comorbidity & $1.4 \pm 1.1$ \\
index, mean \pm SD & \\
\hline
\end{tabular}

IQR interquartile range, $S D$ standard deviation, $C T$ computed tomography carcinoma (7.4\%). When stratified by smoking status, there was significant difference in the histologic type of lung cancer between the current/former smoker group and the never-smoker group (Table 2). The proportion of squamous cell carcinoma and small-cell lung cancer was higher in the current/former smoker group, whereas the proportion of adenocarcinoma was higher in the neversmoker group.

Thirty patients with non-small cell lung cancer had stage I cancer at the time of diagnosis. Of the eight small-cell lung cancer patients, four were at a limited stage when diagnosed. There was no significant difference in the stage of lung cancer at the time of diagnosis according to the smoking status.

\section{Regional association between bronchiectasis and lung cancer}

To assess the locations of $\mathrm{BE}$ and lung cancer, we evaluated 486 lung lobes from 81 patients. Because 4 patients had primary tumors in 2 lobes, the total number of lobes affected with lung cancer was 85 . Lung cancer most commonly involved the right upper lobe (5.6\%), followed by the right lower $(4.1 \%)$ and left upper lobe (3.9 \%) (Table 3). The mean number of lobes affected with $\mathrm{BE}$ per patient was 1.7. The mean severity index of $\mathrm{BE}$ was 8.0 assessed with the modified Bhalla system and 4.4 assessed with the Reiff score, respectively [12, 13]. $\mathrm{BE}$ most commonly involved the left lower lobe $(7.4 \%)$, followed by the right upper (5.6\%), right lower (5.6\%), and left upper $(4.7 \%)$ lobes. Eleven $(2.3 \%)$ lobes contained both $\mathrm{BE}$ and lung cancer. There were 123 (25.3 \%) lobes with BE only and 74 (15.2\%) with lung cancer only. When using the general estimating equation assuming $\mathrm{BE}$ as a risk factor of lung cancer, the calculated $\beta$-value was $-1.091(p=0.001)$ in the analysis of the total lung cancer patients, indicating that the prevalence of lung cancer was significantly lower in lobes with pre-existing BE (Table 4). When analyzing lobes from lung cancer patients separately by smoking status, prevalence of lung cancer remained significantly lower in lobes with preexisting $\mathrm{BE}$ in both the current/former smoker group $(\beta=$ -1.012, $p=0.021)$ and the never-smoker group $(\beta=$ $-1.152, p=0.011)$. When evaluating the lobes stratified by the presence and severity of emphysema of the patients, prevalence of lung cancer was significantly lower in lobes with pre-existing $\mathrm{BE}$ in patients with no or mild emphysema ( $\beta=-1.244, p=0.003)$. Although not statistically significant, similar trends were shown in the lobes in patients with moderate $(\beta=-0.981, p=0.141)$ and severe emphysema $(\beta=-0.673, p=0.318)$.

\section{Discussion}

This study assessed the association between pre-existing $\mathrm{BE}$ and newly diagnosed lung cancer in terms of the 
Table 2 Histologic Types and Staging of Lung Cancer

\begin{tabular}{|c|c|c|c|}
\hline \multirow[t]{2}{*}{ Characteristics } & \multicolumn{2}{|c|}{$\begin{array}{l}\text { Patients with bronchiectasis } \\
\text { and newly diagnosed lung cancer }(n=81)\end{array}$} & \multirow[t]{2}{*}{$p$-value } \\
\hline & $\begin{array}{l}\text { Current/Former smoker } \\
(n=44)\end{array}$ & $\begin{array}{l}\text { Never-smoker } \\
(n=37)\end{array}$ & \\
\hline $\begin{array}{l}\text { Histologic type, } n \\
(\%)\end{array}$ & & & 0.041 \\
\hline $\begin{array}{l}\text { Non-small cell } \\
\text { lung cancer }\end{array}$ & $37(84.1)$ & $36(97.3)$ & \\
\hline Adenocarcinoma & 17 (38.6) & 25 (67.6) & \\
\hline $\begin{array}{l}\text { Squamous cell } \\
\text { carcinoma }\end{array}$ & $14(31.8)$ & $4(10.8)$ & \\
\hline \begin{tabular}{l}
\multicolumn{1}{c}{ Poorly } \\
differentiated \\
carcinoma
\end{tabular} & $3(6.8)$ & $3(8.1)$ & \\
\hline Others & $3(6.8)$ & $4(10.8)$ & \\
\hline $\begin{array}{l}\text { Small cell lung } \\
\text { cancer }\end{array}$ & $7(15.9)$ & $1(2.7)$ & \\
\hline Staging, n (\%) & & & \\
\hline $\begin{array}{l}\text { Non-small cell } \\
\text { lung cancer }\end{array}$ & & & 0.134 \\
\hline I & $12(27.3)$ & 18 (48.6) & \\
\hline$\|$ & $4(9.1)$ & $2(5.4)$ & \\
\hline III & 7 (15.9) & $10(27.0)$ & \\
\hline IV & $14(31.8)$ & $6(16.2)$ & \\
\hline $\begin{array}{l}\text { Small cell lung } \\
\text { cancer }\end{array}$ & & & 0.285 \\
\hline $\begin{array}{l}\text { Limited } \\
\text { disease }\end{array}$ & $3(6.8)$ & $1(2.7)$ & \\
\hline $\begin{array}{l}\text { Extensive } \\
\text { disease }\end{array}$ & $4(9.1)$ & $0(0)$ & \\
\hline
\end{tabular}

lobar distribution. It revealed that the presence of preexisting $\mathrm{BE}$ was associated with a significantly lower risk of lung cancer in the same lobe. These results are interesting and suggest another aspect of the relationship between chronic inflammatory airway diseases and lung cancer. In addition, our data also provide information about the prevalent location of lung cancer and $\mathrm{BE}$ in patients which the two diseases coexist. Compared to lung cancer, which most commonly involved the right upper lobe, BE most commonly involved the left lower lobe. To our knowledge, this would be the first description of the association between $\mathrm{BE}$ and lung cancer by location of the disease detected using $\mathrm{CT}$ at the level of lung lobes $[6,17]$.

There is limited evidence for the pathophysiological mechanism of the protective effect of $\mathrm{BE}$ in local carcinogenesis shown in our study. However, indirect biological plausibility exists. There are reports of elevated serum TGF- $\beta 1$ levels in patients with BE [5]. In normal and premalignant cells, TGF- $\beta$ enforces homeostasis and tumor-suppressive effects by regulating cell-autonomous
Table 3 Lobar Distribution and Characteristics of Lung Cancer and Bronchiectasis

\begin{tabular}{|c|c|}
\hline Characteristics & Total 486 lobes in 81 patients \\
\hline \multicolumn{2}{|l|}{ Affected lobes with lung cancer } \\
\hline RUL, n (\%) & $27(5.6)$ \\
\hline RML, n (\%) & $5(1.0)$ \\
\hline RLL, n (\%) & $20(4.1)$ \\
\hline LUL, n (\%) & $19(3.9)$ \\
\hline Lingula, n (\%) & $1(0.2)$ \\
\hline LLL, n (\%) & $13(2.7)$ \\
\hline $\begin{array}{l}\text { Number of lobes affected } \\
\text { with BE per patients, mean } \pm \text { SD }\end{array}$ & $1.7 \pm 0.8$ \\
\hline \multicolumn{2}{|l|}{ Affected lobes with BE } \\
\hline RUL, n (\%) & $27(5.6)$ \\
\hline RML, n (\%) & $16(3.3)$ \\
\hline RLL, n (\%) & $26(5.6)$ \\
\hline LUL, n (\%) & $23(4.7)$ \\
\hline Lingula, n (\%) & $6(1.2)$ \\
\hline LLL, n (\%) & $36(7.4)$ \\
\hline $\begin{array}{l}\text { BE severity index } \\
\text { (modified Bhalla system), mean } \pm S D\end{array}$ & $8.0 \pm 5.9$ \\
\hline $\begin{array}{l}\text { BE severity index (Reiff score), } \\
\text { mean } \pm S D\end{array}$ & $4.4 \pm 2.1$ \\
\hline $\begin{array}{l}\text { Lobes with combined BE } \\
\text { and lung cancer, } \mathrm{n}(\%)\end{array}$ & $11(2.3)$ \\
\hline Lobes with BE only, n (\%) & $123(25.3)$ \\
\hline Lobes with lung cancer only, n (\%) & $74(15.2)$ \\
\hline
\end{tabular}

$B E$ bronchiectasis, $S D$ standard deviation, RUL right upper lobe, $R M L$ right middle lobe, RLL right lower lobe, LUL left upper lobe, LLL left lower lobe

cytostasis, differentiation, and apoptosis. In addition to its direct inhibitory effects, TGF- $\beta$ can restrict epithelial cell proliferation and carcinogenesis by blocking the production of paracrine factors in the stromal cells $[8,9]$. Other plausibility includes the CTFR gene. A case-control study suggested that the $\triangle \mathrm{F} 508$ deletion in the CFTR gene in patients with cystic fibrosis, which shows radiological features of $\mathrm{BE}$, is an important protective variant for lung cancer risk [10]. However, more research is needed to identify a biological mechanism that can clearly explain our findings.

Since previous studies report a positive association between the chronic inflammation in COPD or smoking and the risk of squamous cell carcinoma, it is notable that the majority of patients in our study were diagnosed with adenocarcinoma $[2,18]$. Moreover, among the patients diagnosed with lung cancer, $46 \%$ were neversmokers, and $65 \%$ had no or mild emphysema. The high proportion of adenocarcinoma, never-smokers, and nonemphysematous subjects among the diagnosed lung cancer patients suggests that the majority of lung cancers in patients with pre-existing $\mathrm{BE}$ occurs independently of 
Table 4 Risk of Lung Cancer in Patients with Underlying Bronchiectasis Estimated by General Estimating Equation ${ }^{a}$

\begin{tabular}{llll}
\hline Population & $\beta$-value & $95 \% \mathrm{Cl}$ & $p$-value \\
\hline Total & -1.091 & $-1.716--0.466$ & 0.001 \\
Classified by smoking history & & & \\
$\quad$ Current/Former smoker & -1.012 & $-1.869--0.155$ & 0.021 \\
$\quad$ Never-smoker & -1.152 & $-2.043--0.261$ & 0.011 \\
Classified by emphysema severity & & \\
$\quad$ No/mild emphysema & -1.244 & $-2.075--0.412$ & 0.003 \\
$\quad$ Moderate emphysema & -0.981 & $-2.287-0.325$ & 0.141 \\
$\quad$ Severe emphysema & -0.673 & $-1.995-0.649$ & 0.318 \\
\hline a
\end{tabular}

${ }^{a} \beta$-value calculated by evaluating bronchiectasis as a risk factor of lung cancer

chronic inflammation. These findings can support our theory that the chronic inflammation caused by $\mathrm{BE}$ is not associated with an increased risk of lung cancer.

Previous epidemiological reports have aimed to evaluate the association between prior lung diseases and the risk of lung cancer. They showed that some chronic respiratory diseases, including bronchitis and emphysema, are positively associated with the risk of lung cancer [17, 19]. However, these efforts focused mainly on evaluating diseases and chronic inflammation associated with smoking, a major contributor to lung cancer. To date, the mechanism of airway inflammation in $\mathrm{BE}$, and the association between $\mathrm{BE}$ and lung cancer remains unclear. Recently, a nationwide cohort study from Taiwan reported that patients with underlying $\mathrm{BE}$ had a 2.36 -fold increased risk of lung cancer compared to patients without BE. However, this study has limitations in confirming the disease status only by the diagnosis codes provided from the registered hospitals, and including only inpatients as subjects diagnosed with $\mathrm{BE}$, who had significantly higher rate of comorbidities possibly related to cancer. Moreover, the study used a database that did not contain information on smoking status of the participants, which is a possible strong confounding factor when evaluating risk of lung cancer. The study also could not provide any information about the severity or location of $\mathrm{BE}$ and the histological type of lung cancer, which is important when discussing the possible effects of $\mathrm{BE}$ and inflammation on the risk of lung cancer [20]. Although our study included a relatively small number of subjects, we were able to obtain detailed information about the diagnosed $\mathrm{BE}$ and lung cancer for each patient, and the data on the location of $\mathrm{BE}$ and lung cancer made it possible to perform analyses within levels of lung lobes. Results of our study are in concordance with a recent case-control study from South Korea which reported that the concomitant presence of $\mathrm{BE}$ was associated with a lower risk of lung cancer in COPD patients [21]. Although $\mathrm{BE}$ is a representative chronic inflammatory airway disease causing permanent dilatation of the bronchi and is accompanied by high levels of inflammatory cytokines, our results suggest that the chronic inflammation caused by BE might produce different cytokines compared with other airway diseases and acts in a different way in carcinogenesis of the lung.

The main strength of our study is that the presence of lung cancer and BE was assessed with chest $\mathrm{CT}$, a precise means of evaluating the location of the disease at the level of the lung lobes. In addition, because we analyzed the association between the two diseases by location within patients known to have both diseases, the possible confounding factors of the risk of lung cancer in each patient (e.g., age, gender, and smoking status) could be ignored in our study.

To interpret our results correctly, we should consider the limitations of this study. First, given its retrospective design, by selecting patients who were diagnosed with lung cancer, there might have been selection bias enrolling patients at higher risk of, or more susceptible to, lung cancer. However, since the study design was powered to evaluate the association between $\mathrm{BE}$ and lung cancer by the locations of the two diseases within each subject, rather than an epidemiology study evaluating a certain population, possible selection bias is not expected to have contributed to the significant results of our study. Second, our data contains no detailed clinical information on the history of BE (e.g. frequency of exacerbations, type of infection, length of follow up, and received treatments), which can be an important issue when discussing the role of chronic inflammation in $\mathrm{BE}$. Lastly, due to the limited data collected on the field of inflammation and carcinogenesis related $\mathrm{BE}$, the validity of the potential explanations on our findings and the role of chronic inflammation might be low. Nevertheless, considering the limited data and difficulty to perform large-scaled studies on the association between $\mathrm{BE}$ and lung cancer, our results still would provide novel and relevant information, and motivation for further studies.

Although this study was not a longitudinal study following $\mathrm{BE}$ patients, it is reasonable to believe that in the patients evaluated in our study, BE preceded the development of lung cancer since BE is generally accepted to be a chronic condition following infection in childhood, while lung cancer usually develops within years of the initial diagnosis [22]. Moreover, patients were excluded if they had BE secondary to mechanical effects caused by lung cancer. Therefore, despite the retrospective design, we insist that our results represent a temporal relationship between $\mathrm{BE}$ and lung cancer, rather than a coincidental finding.

\section{Conclusions}

Regionally, pre-existing BE was associated with a lower risk of the occurrence of lung cancer in the same lobe. 


\section{Additional file}

Additional file 1: Figure S1. Example CT images of $(A)$ underlying bronchiectasis and newly diagnosed lung cancer existing in the same lobe and (B) secondary traction bronchiectasis caused by lung cancer. (ZIP $7247 \mathrm{~kb})$

\section{Abbreviations}

BE: Bronchiectasis; COPD: Chronic obstructive pulmonary disease: CT: Computed tomography; IQR: Interquartile range; LLL: Left lower lobe; LUL: Left upper lobe; RLL: Right lower lobe; RML: Right middle lobe; RUL: Right upper lobe; SD: Standard deviation; TGF- $\beta 1$ : Transforming growth factor- $\beta 1$

\section{Acknowledgements}

This study was non-financially supported by a multidisciplinary research grant-in-aid from the Seoul Metropolitan Government Seoul National University (SMG-SNU) Boramae Medical Center.

\section{Funding}

None declared.

\section{Availability of data and materials}

The datasets analyzed during the current study available from the corresponding author on reasonable request.

\section{Authors' contributions}

YWK, and DKK contributed to conceiving and designing the study, data collection, interpreting the data, writing the manuscript, and approving the final version of the manuscript. CHL, KNJ, JKL, EYH, SSP, and HSC contributed substantially to the study design, data analysis and interpretation, and the writing of the manuscript. All authors read and approved the final manuscript.

\section{Competing interests}

The authors declare that they have no competing interests.

\section{Consent for publication}

Not applicable.

\section{Ethics approval and consent to participate}

The design of this study was approved by the Institutional Review Board of Seoul National University Hospital (IRB No. H-1312-123-547) and Seoul National University Boramae Hospital (IRB No. 16-2014-137). The institutional review boards waived the need for written informed consent from the participants.

\section{Author details}

'Division of Pulmonary and Critical Care Medicine, Department of Internal Medicine, Seoul National University College of Medicine, Seoul, Republic of Korea. ${ }^{2}$ Department of Radiology, Seoul National University College of Medicine, Seoul Metropolitan Government-Seoul National University Boramae Medical Center, Seoul, Republic of Korea. ${ }^{3}$ Division of Pulmonary and Critical Care Medicine, Department of Internal Medicine, Seoul Nationa University College of Medicine, Seoul Metropolitan Government-Seoul National University Boramae Medical Center, 20 Boramaero-5-Gil, Dongjak-Gu, Seoul 156-707, Republic of Korea.

Received: 4 July 2016 Accepted: 7 November 2016

Published online: 15 November 2016

\section{References}

1. Vakkila J, Lotze MT. Inflammation and necrosis promote tumour growth. Nat Rev Immunol. 2004:4(8):641-8.

2. Raviv S, Hawkins KA, DeCamp Jr MM, Kalhan R. Lung cancer in chronic obstructive pulmonary disease: enhancing surgical options and outcomes. Am J Respir Crit Care Med. 2011;183(9):1138-46.

3. Malkinson AM. Role of inflammation in mouse lung tumorigenesis: a review. Exp Lung Res. 2005;31(1):57-82.
4. Takiguchi Y, Sekine I, Iwasawa S, Kurimoto R, Tatsumi K. Chronic obstructive pulmonary disease as a risk factor for lung cancer. World J Clin Oncol. 2014 5(4):660-6.

5. Mak JC, Ho SP, Leung RY, Ho PL, Ooi C, Tipoe GL, et al. Elevated levels of transforming growth factor-beta(1) in serum of patients with stable bronchiectasis. Respir Med. 2005;99(10):1223-8.

6. de Torres JP, Bastarrika G, Wisnivesky JP, Alcaide AB, Campo A, Seijo LM, et al. Assessing the relationship between lung cancer risk and emphysema detected on low-dose CT of the chest. Chest. 2007;132(6):1932-8.

7. Lowenfels AB, Maisonneuve P, Cavallini G, Ammann RW, Lankisch PG, Andersen JR, et al. Pancreatitis and the risk of pancreatic cancer. International pancreatitis study group. N Engl J Med. 1993;328(20):1433-7.

8. Vendramini-Costa DB, Carvalho JE. Molecular link mechanisms between inflammation and cancer. Curr Pharm Des. 2012;18(26):3831-52.

9. Massague J. TGFbeta in cancer. Cell. 2008;134(2):215-30.

10. Li Y, Sun Z, Wu Y, Babovic-Vuksanovic D, Li Y, Cunningham JM, et al. Cystic fibrosis transmembrane conductance regulator gene mutation and lung cancer risk. Lung Cancer. 2010;70(1):14-21.

11. Pasteur MC, Bilton D, Hill AT, British Thoracic Society Bronchiectasis non CFGG. British thoracic society guideline for non-CF bronchiectasis. Thorax. 2010;65 Suppl 1:i1-i58.

12. Habesoglu MA, Tercan F, Ozkan U, Fusun EO. Effect of radiological extent and severity of bronchiectasis on pulmonary function. Multidiscip Respir Med. 2011:6(5):284-90

13. Reiff DB, Wells AU, Carr DH, Cole PJ, Hansell DM. CT findings in bronchiectasis: limited value in distinguishing between idiopathic and specific types. AJR Am J Roentgenol. 1995;165(2):261-7.

14. Goddard PR, Nicholson EM, Laszlo G, Watt I. Computed tomography in pulmonary emphysema. Clin Radiol. 1982;33(4):379-87.

15. Makita $H$, Nasuhara $Y$, Nagai $K$, Ito $Y$, Hasegawa $M$, Betsuyaku T, et al. Characterization of phenotypes based on severity of emphysema in chronic obstructive pulmonary disease. Thorax. 2007;62(11):932-7.

16. Sekine $Y$, Fujisawa $T$, Suzuki $K$, Tsutatani $S$, Kubota $K$, Ikegami $H$, et al. Detection of chronic obstructive pulmonary disease in community-based annual lung cancer screening: chiba chronic obstructive pulmonary disease lung cancer screening study group. Respirology. 2014;19(1):98-104.

17. Mayne ST, Buenconsejo J, Janerich DT. Previous lung disease and risk of lung cancer among men and women nonsmokers. Am J Epidemiol. 1999; 149(1):13-20.

18. Papi A, Casoni G, Caramori G, Guzzinati I, Boschetto P, Ravenna F, et al. COPD increases the risk of squamous histological subtype in smokers who develop non-small cell lung carcinoma. Thorax. 2004;59(8):679-81.

19. Denholm R, Schuz J, Straif K, Stücker I, Jöckel KH, Brenner DR, et al. Is previous respiratory disease a risk factor for lung cancer? Am J Respir Crit Care Med. 2014;190(5):549-59.

20. Chung WS, Lin $\mathrm{CL}$, Hsu WH, Kao CH. Increased risk of lung cancer among patients with bronchiectasis: a nationwide cohort study. QJM. 2016;109(1): 17-25. doi:http://dx.doi.org/10.1093/qjmed/hcu237. Accessed 11 Nov 2016.

21. Kim YW, Jin KN, Heo EY, Park SS, Chung HS, Kim DK. The association between combined non-cystic fibrosis bronchiectasis and lung cancer in patients with chronic obstructive lung disease. Int J Chron Obstruct Pulmon Dis. 2015;10(1):873-9.

22. Barker AF. Bronchiectasis. N Engl J Med. 2002;346(18):1383-93.

\section{Submit your next manuscript to BioMed Central and we will help you at every step:}

- We accept pre-submission inquiries

- Our selector tool helps you to find the most relevant journal

- We provide round the clock customer support

- Convenient online submission

- Thorough peer review

- Inclusion in PubMed and all major indexing services

- Maximum visibility for your research

Submit your manuscript at www.biomedcentral.com/submit 